\title{
不飽和流れの表現
}

\section{日比義彦* \\ Expression for water flow in the unsaturated soil}

\author{
Yoshihiko HIBI *
}

\section{1.一般的な不飽和流れの表現}

地下水の流れの支配方程式は質量保存の法則と ダルシーの法則より誘導できる。質量保存の式は 以下のようになる。

$$
\frac{\partial \rho_{w} \theta_{w}}{\partial t}+\frac{\partial \rho_{w} V_{x}}{\partial x}+\frac{\partial \rho_{w} V_{y}}{\partial y}+\frac{\partial \rho_{w} V_{z}}{\partial z}=0
$$

ここで、 $\theta_{w}$ は体積含水率 [無次元]、 $\rho_{w}$ は水の密 度 $\left[\mathrm{M} / \mathrm{L}^{3}\right] 、 V_{x} 、 V_{y}$ と $V_{z}$ はそれぞれ $x 、 y 、 z$ 方向の 流速、 $t$ は時間 $[\mathrm{T}]$ である。なお、 $x$ と $y$ はそれ ぞれ $x 、 y$ 軸方向の座標であり、 $z$ は上向きを正と する重力方向の座標である。 $V_{x} 、 V_{y}$ と $V_{z}$ は以下の ダルシーの法則より求めることができる。

$$
\begin{gathered}
V_{x}=-k_{r}\left(\theta_{w}\right) K_{s} \frac{\partial \psi_{w}}{\partial x} \quad V_{y}=-k_{r}\left(\theta_{w}\right) K_{s} \frac{\partial \psi_{w}}{\partial y} \\
V_{z}=-k_{r}\left(\theta_{w}\right) K_{s} \frac{\partial\left(\psi_{w}+\rho_{r w} z\right)}{\partial z}
\end{gathered}
$$

ここで、 $\psi_{w}$ は圧力水頭 $[\mathrm{L}] 、 k_{r}\left(\theta_{w}\right)$ は相対透水 係数または相対透過度 [無次元]、 $K_{s}$ は飽和状態 の透水係数 $[\mathrm{L} / \mathrm{T}] 、 \rho_{r w}$ は基準とする水の密度に対 する水の相対密度 [無次元] である。

式（2）を式（1）に代入すると以下の飽和・不 飽和の地下水の流れの支配方程式を求めることが できる。

$$
\begin{aligned}
& \frac{\partial \rho_{w} \theta_{w}}{\partial t}=\frac{\partial}{\partial x}\left(\rho_{w} k_{r}\left(\theta_{w}\right) K_{s} \frac{\partial \psi_{w}}{\partial x}\right)+\frac{\partial}{\partial y}\left(\rho_{w} k_{r}\left(\theta_{w}\right) K_{s} \frac{\partial \psi_{w}}{\partial y}\right) \\
& +\frac{\partial}{\partial z}\left(\rho_{w} k_{r}\left(\theta_{w}\right) K_{s} \frac{\partial\left(\psi_{w}+\rho_{r v} z\right)}{\partial z}\right)
\end{aligned}
$$

さらに、間隙率 $n$ [無次元 $]$ と水の飽和度 $S_{w}$ [無 次元］より体積含水率は $\theta=n S_{w}$ となり、式（3） は以下のように変形することができる。

$$
\begin{aligned}
\theta_{w} & \frac{\partial \rho_{w}}{\partial \psi_{w}} \frac{\partial \psi_{w}}{\partial t}+\rho_{w} S_{w} \frac{\partial n}{\partial \psi_{w}} \frac{\partial \psi_{w}}{\partial t}+\rho_{w} n \frac{\partial S_{w}}{\partial t} \\
= & \frac{\partial}{\partial x}\left(\rho_{w} k_{r}\left(\theta_{w}\right) K_{s} \frac{\partial \psi_{w}}{\partial x}\right)+\frac{\partial}{\partial y}\left(\rho_{w} k_{r}\left(\theta_{w}\right) K_{s} \frac{\partial \psi_{w}}{\partial y}\right) \\
& +\frac{\partial}{\partial z}\left(\rho_{w} k_{r}\left(\theta_{w}\right) K_{s} \frac{\partial\left(\psi_{w}+\rho_{r w} z\right)}{\partial z}\right)
\end{aligned}
$$

式 (4) の左辺の第 1 項は水の圧縮性を表し、第 2 項は土の間隙の変化を示している。不飽和状態で は、一般的に水の圧縮や間隙の変化を考慮しない が、飽和状態では、水の圧縮と間隙の変化を考慮 する場合が多い。たたし、水の圧縮性を考慮する 際には、地下水の密度が带水層内で一様に変化す るために空間的な変化が生じないと仮定する場合 が多い（P.A. ドミンコら 1995）。そのように仮 定すると飽和状態の式 (4) の右辺の $\rho_{w}$ は微分の外 に出すことができ、 $S_{w}=1 、 \theta_{w}=n$ として式 (4) の両辺を $\rho_{w}$ で除すると式 (4) の左辺の第 1 項と第 2 項は $\left(1 / \rho_{w}\right)\left(n \partial \rho_{w} / \partial \psi_{w}+\rho_{w} \partial n / \partial \psi_{w}\right) \partial \psi_{w} / \partial t$ と なり、 $\left(n \partial \rho_{w} / \partial \psi_{w}+\rho_{w} \partial n / \partial \psi_{w}\right) / \rho_{w}$ は比貯留係

名城大学理工学部環境創造学科 ( 
数 $S_{S}[1 / \mathrm{L}]$ となる。従って、飽和・不飽和状態の 地下水の支配方程式は式（4）より以下の式（5） のように表すことができる。なお、前記のように 不飽和状態では一般的に水の圧縮や間隙の変化を 考慮しないので $S_{S}=0$ となる。そこで、式 (5) の左辺の第 1 項が飽和状態の場合に有効になるよ うに、飽和の場合に 1 、不飽和の場合に 0 とする $\alpha$ を式（5）の左辺の第 1 項に乗じている。

$$
\begin{aligned}
& \alpha S_{s} \frac{\partial \psi_{w}}{\partial t}+n \frac{\partial S_{w}}{\partial t}=\frac{\partial}{\partial x}\left(k_{r}\left(\theta_{w}\right) K_{s} \frac{\partial \psi_{w}}{\partial x}\right) \\
& +\frac{\partial}{\partial y}\left(k_{r}\left(\theta_{w}\right) K_{s} \frac{\partial \psi_{w}}{\partial y}\right)+\frac{\partial}{\partial z}\left\{k_{r}\left(\theta_{w}\right) K_{s} \frac{\partial\left(\psi_{w}+\rho_{r w} z\right)}{\partial z}\right\}
\end{aligned}
$$

（不飽和 $\alpha=0 \quad$ 飽和 $\alpha=1 ）$

式 (5) では、右辺に含まれる $\psi_{w}$ と $k_{r}\left(\theta_{w}\right) 、 さ$ らに、左辺に含まれる $S_{w}$ で不飽和を表している。 これらは、不飽和領域のサクション $-\psi_{w}$ と $\theta_{w}$ (または $S_{w}$ ) の関係である水分特性曲線および相 対透水係数 $k_{r}\left(\theta_{w}\right)$ と $\theta_{w}\left(\right.$ または $\left.S_{w}\right)$ の関係によ り関連付けられている。なお、飽和状態では、 $S_{w}=1$ となることより式（5）の左辺の第 2 項は 0 となり、右辺の相対透水係数は $k_{r}(n)=1$ とな る。式 (5) では水の飽和度と圧力水頭が混在して いることより混合型方程式と呼ばれる場合があ る。

\section{2. 広く知られている不飽和流れの表現}

浸透流解析は、昭和50年代なかばより堤防の漏 水、トンネル施工による地下水変動や掘削工事に 伴う地下水位低下などの地下水流動に関わる問題 について頻繁に使われるようになった。当初は、 大型コンピューターなどを使用していたが、コン ピューターの技術の発展により次第に浸透流解析 がパーソナルコンピューターなどを用いて容易に 出来るようになった。大型コンピューターを使用 していた時代から使われてきた浸透流解析プログ ラムに赤井らにより開発されたUNSAFがある。 このプログラムの詳細は赤井ら（1977）に記載さ れており、論文中では地下水の不飽和流れの支配 方程式を以下のように求めている。

不飽和状態では、前記したように水の圧縮が生 じないものとする。また、 $k_{r}\left(\theta_{w}\right)$ は間接的では
あるが水分特性曲線を用いて $\psi_{w}$ の関数とするこ とができるので $k_{r}\left(\psi_{w}\right)$ と表す。従って、式 (3) は以下のようになる。

$$
\begin{aligned}
\frac{\partial \theta_{w}}{\partial t} & =\frac{\partial}{\partial x}\left(k_{r}\left(\psi_{w}\right) K_{s} \frac{\partial \psi_{w}}{\partial x}\right)+\frac{\partial}{\partial y}\left(k_{r}\left(\psi_{w}\right) K_{s} \frac{\partial \psi_{w}}{\partial y}\right) \\
+ & \frac{\partial}{\partial z}\left(k_{r}\left(\psi_{w}\right) K_{s} \frac{\partial\left(\psi_{w}+\rho_{r w} z\right)}{\partial z}\right)
\end{aligned}
$$

ここで、式（6）の左辺の $\partial \theta_{w} / \partial t$ を $\partial \theta_{w} / \partial t=$ $\left(\partial \theta_{w} / \partial \psi_{w}\right) \partial \psi_{w} / \partial t$ のように変形すると $\partial \theta_{w} / \partial \psi_{w}$ が比水分容量 $C\left(\psi_{w}\right)$ となるので、式 (6) の左辺 は $\partial \theta_{w} / \partial \mathrm{t}=\mathrm{C}\left(\psi_{w}\right) \partial \psi_{w} / \partial t$ となる。また、飽和状 態の帯水層内では地下水の密度が一様に変化する ために空間的な変化が生じないと仮定すると式 (4) は以下のようになる。

$$
\begin{gathered}
\frac{1}{\rho_{w}}\left(n \frac{\partial \rho_{w}}{\partial \psi_{w}}+\rho_{w} \frac{\partial n}{\partial \psi_{w}}\right) \frac{\partial \psi_{w}}{\partial t}=\frac{\partial}{\partial x}\left(K_{s} \frac{\partial \psi_{w}}{\partial x}\right) \\
\quad+\frac{\partial}{\partial y}\left(K_{s} \frac{\partial \psi_{w}}{\partial y}\right)+\frac{\partial}{\partial z}\left\{K_{s} \frac{\partial\left(\psi_{w}+\rho_{r w} z\right)}{\partial z}\right\}
\end{gathered}
$$

前記したように式 (7) の左辺は $S_{s}=\left(n \partial \rho_{w} / \partial \psi_{w}\right.$ $\left.+\rho_{w} \partial n / \partial \psi_{w}\right) / \rho_{w}$ となる。式 (6) と式 (7) を考 慮すると以下の飽和・不飽和の地下水の支配方程 式が誘導される。

$$
\begin{aligned}
& \left(\alpha S_{s}+C\left(\psi_{w}\right)\right) \frac{\partial \psi_{w}}{\partial t}=\frac{\partial}{\partial x}\left(k_{r}\left(\psi_{w}\right) K_{s} \frac{\partial \psi_{w}}{\partial x}\right) \\
& +\frac{\partial}{\partial y}\left(k_{r}\left(\psi_{w}\right) K_{s} \frac{\partial \psi_{w}}{\partial y}\right)+\frac{\partial}{\partial z}\left\{k_{r}\left(\psi_{w}\right) K_{s} \frac{\partial\left(\psi_{w}+\rho_{r w} z\right)}{\partial z}\right\}
\end{aligned}
$$

（不飽和 $\alpha=0 \quad$ 飽和 $\alpha=1 ）(8 ）$

式 (8) の左辺の時間項に注目すると、不飽和状 態の場合には $C\left(\psi_{w}\right)<0 、 \alpha S_{S}=0$ となり、飽和 状態では $C\left(\psi_{w}\right)=0 、 \alpha S_{S}>0$ となる。また、 $C\left(\psi_{w}\right)$ と $k_{r}\left(\psi_{w}\right)$ は $\psi_{w}$ の関数となり、式 (8) の中 で不飽和特性を表現している。式 (8)では飽和度 が含まれておらず、水の圧力水頭のみの支配方程 式となっているので圧力型方程式と呼ばれる場合 がある。

式 (8) を有限要素法や差分法などで定式化した 場合に、 $C\left(\psi_{w}\right)$ が解析結果に与える影響について 国内ではあまり検討や議論がされていない。しか し、海外では、すでに、この式（8）の問題が Celia and Bouloutas (1990) によって指摘されてい る。Celia and Bouloutas（1990）は比貯留係数を 考慮しない式 (8) を差分法とガラーキン型有限要 
素法で定式化し、初期状態が不飽和となる一次元 の吸水問題を解いた。その結果、式（8）を用いた 場合には境界における水の収支と解析領域内に溜 まる水の量が差分法とガラーキン型有限要素法の 両方ともに一致しないことを確認している。ま た、日比ら（2002）はNAPL と水の 2 相流に関す る支配方程式を式 (8) のように比水分容量を用い て有限要素法で定式化し、一次元領域について排 水過程と吸水過程を解析した。その結果、境界の NAPL の収支と領域内の NAPL の変化量が一致し ないことを確認している。両者ともに式 (8) のよ うな非保存系の圧力型支配方程式をガラーキン型 有限要素法または差分法で定式化することに問題 があることを指摘している。

図 1 に示すように不飽和の一次元領域を間隔 $L$ で要素分割し、節点 1 から $N$ 毎にガラーキン型有 限要素法で $S_{S}=0$ の場合の式（5）を離散化する と各節点で代数方程式が得られる。飽和度と間隙 率の積が体積含水率となることを考慮して、得ら れたすべての節点の代数方程式の総和をとると以 下のようなマスバランスの式が得られる。

$$
\begin{aligned}
& L\left[\frac{\theta_{\mathrm{w} 1}^{n+1, m+1}-\theta_{\mathrm{w} 1}^{n}}{2}+\sum_{i=2}^{N-1}\left(\theta_{\mathrm{w} i}^{n+1, m+1}-\theta_{\mathrm{w} i}{ }^{n}\right)\right. \\
& \left.+\frac{\theta_{\mathrm{w} N}^{n+1, m+1}-\theta_{\mathrm{w} N}{ }^{n}}{2}\right]=\left(q_{\mathrm{w} 1}^{n+1}+q_{\mathrm{w} N}^{n+1}\right) \Delta t
\end{aligned}
$$

ここで、下付きの文字は節点番号、上付きの文字 の $n$ は時間ステップ数、 $m$ は非線形解析のための 繰り返し回数、 $q_{\mathrm{w} 1}{ }^{n+1}$ と $q_{\mathrm{w} N}{ }^{n+1}$ は境界である節点 1 と $\mathrm{N}$ におけるそれぞれの流量、 $\Delta t$ は時間間隔 を示す。式 (9) の左辺は解析領域に貯留される水 の体積を示し、右辺は境界での水の流入、流出量 （体積）を表している。式（9）では右辺の解析領 域内に貯留される水の量と境界における水の収支 量が等しいことを示している。従って、式 (9) で
はマスバランスが時間ステップ毎に維持されるこ とが分かる。

一方、同じ条件で式 (8) を節点毎にガラーキン 型有限要素法で離散化して得た代数方程式の総和 をとると以下のマスバランスの式が得られる。

$$
\begin{gathered}
\frac{\bar{C}_{1,2}^{n+1, m} L}{2}\left(\psi_{\mathrm{w} 1}^{n}-\psi_{w 1}^{n+1, m+1}\right) \\
+\sum_{i=2}^{N-1} \frac{\left(\bar{C}_{i-1, i}^{n+1, m}+\bar{C}_{i, i+1}^{n+1, m}\right) L}{2}\left(\psi_{\mathrm{w} i}^{n}-\psi_{\mathrm{w} i}^{n+1, m+1}\right) \\
+\frac{\bar{C}_{N-1, N}^{n+1, m} L}{2}\left(\psi_{\mathrm{w} N}^{n}-\psi_{\mathrm{w} N}^{n+1, m+1}\right) \\
=\left(q_{w 1}^{n+1}+q_{w N}^{n+1}\right) \Delta \mathrm{t}
\end{gathered}
$$

ここで、 $\bar{C}_{i-1, i}$ は節点 $i-1$ と $i$ で構成される要素の 比水分容量の平均であり、また、下付きの文字は 節点番号、上付きの文字の $n$ は時間ステップ数、 $m$ は非線形解析のための繰り返し回数、 $q_{\mathrm{w} 1}{ }^{n+1}$ と $q_{\mathrm{w} N}{ }^{n+1}$ は境界である節点 1 と $\mathrm{N}$ におけるそれぞれ の流量、 $\Delta t$ は時間間隔を示す。式 (10) の右辺は 式 (9) と同様に境界における水の収支を示してい る。式 (10) の左辺についても式 (9) と同様に解 析領域内に貯留される水の量を示すが式 (9) のよ うに体積含水率で直接的に解析領域内に貯留され る水の量を表していない。比水分容量の定義であ る $C=\Delta \theta_{w} / \Delta \psi_{w}$ より体積含水率の変化は $\Delta \theta_{w}=$ $C \Delta \psi_{w}$ で得ることができる。式（10）では節点 $i-1$ と節点 $i て ゙$ 構成される要素の比水分容量の平均 值と節点 $i$ と節点 $i+1$ で構成される要素の比水分 容量の平均をさらに平均した $\left(\bar{C}_{i-1, i}^{n+1, n}+\bar{C}_{i, i+1}^{n+1, m}\right) / 2$ に $\psi_{\mathrm{w} i}{ }^{n}-\psi_{\mathrm{w} i}{ }^{n+1, m+1}$ を乗じて解析領域内の体積含 水率の前の時間ステップからの変化量である $\theta_{\mathrm{w} i}{ }^{n+1, m+1}-\theta_{\mathrm{w} i}{ }^{n}$ を求めている。後述するように体 積含水率または水の飽和度とサクションとの関係 を示す水分特性曲線は非線形であり、それに伴い 比水分容量も一定でなくなる。そうすると、図 2

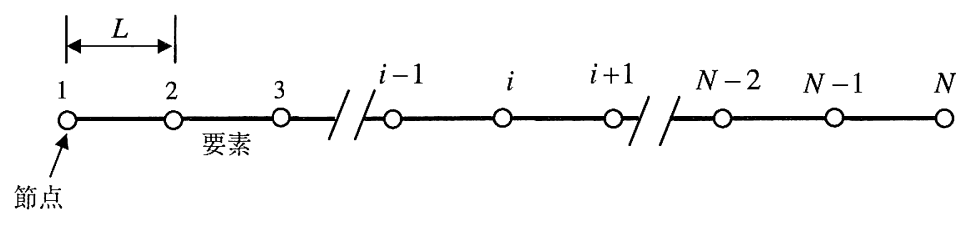

図 1 一次元の節点と要素 


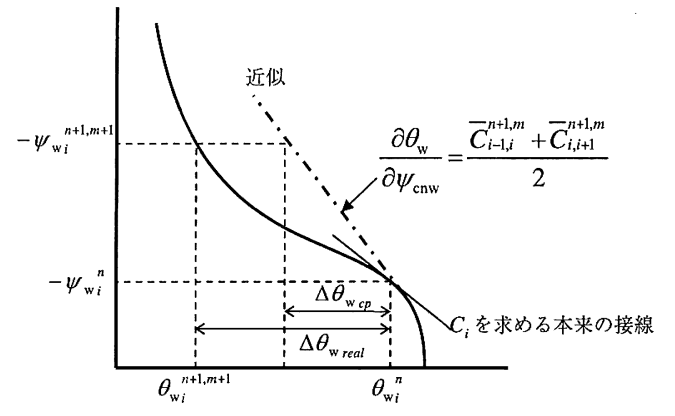

図 2 実際の水分特性曲線（Cが一定でない場合）

に示すように本来の比水分容量の值と異なる比水 分容量の平均值を用いるためにマスバランスが維 持されない場合が生じる。当然、図 3 に示すよう に比水分容量が一定になるような水分特性曲線を 用いる場合には式（10）はマスバランスが維持さ れる。また、時間間隔を短くすれば、本来の比水 分容量に $\left(\bar{C}_{i-1, i}^{n+1, m}+\bar{C}_{i, i+1}^{n+1, m}\right) / 2$ が近似的に等しくなる ために、解析領域内に貯留される水の量と境界に おける水の収支が等しくなる。ただし、図 3 のよ うな水分特性曲線を用いることは現実的ではな く、また、解析の時間間隔を短くすることにも限 界がある。

式 (5) の混合型方程式に非線形解法の Picard 法 を、時間の定式化には後退差分法を適用し、さら にガラーキン型有限要素法で定式化すると以下の 式（11）のようになる。

$$
\begin{aligned}
& \alpha S_{s} \sum_{j=1}^{n p} \int_{V} \phi_{i} \phi_{j} d V \frac{\psi_{w j}^{n+1, m+1}-\psi_{w j}^{n}}{\Delta t} . \\
& +n \sum_{j=1}^{n p} \int_{V} \phi_{i} \phi_{j} d V \frac{S_{w j}^{n+1, m+1}-S_{w j}^{n}}{\Delta t} . \\
& +\sum_{j=1}^{n p}\left(\int_{V} \bar{k}_{r}\left(\theta_{w}\right)^{n+1, m} K_{s} \frac{\partial \phi_{i}}{\partial x} \frac{\partial \phi_{j}}{\partial x} d V\right. \\
& +\int_{V} \bar{k}_{r}\left(\theta_{w}\right)^{n+1, m} K_{s} \frac{\partial \phi_{i}}{\partial y} \frac{\partial \phi_{j}}{\partial y} d V \\
& \left.+\int_{V} \bar{k}_{r}\left(\theta_{w}\right)^{n+1, m} K_{s} \frac{\partial \phi_{i}}{\partial z} \frac{\partial \phi_{j}}{\partial z} d V\right) \psi_{j}^{n+1, m+1}
\end{aligned}
$$

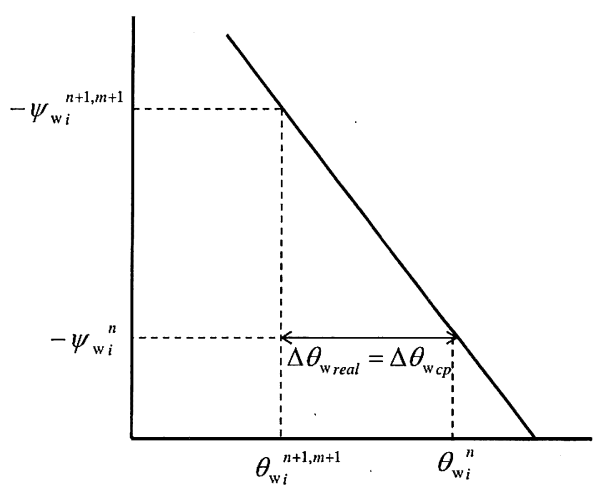

図 3 水分特性曲線（Cが一定な場合）

$$
=-\int_{V} \rho_{r w} k_{r}\left(\theta_{w}\right)^{n+1, m} K_{s} \frac{\partial \phi_{i}}{\partial z} d V+q_{w i}(i=1 \sim n p)
$$

ここで、 $\phi$ は形状関数、npは全節点数、 $\bar{k}_{r}\left(\theta_{w}\right)^{n+1, m}$ は $k_{r}\left(\theta_{w}\right)$ の要素毎の平均、 $q_{\mathrm{w} i}{ }^{n+1}$ は解析領域境界 の節点に抢ける水の流量 $\left[\mathrm{L}^{3} / \mathrm{T}\right] 、 \mathrm{~V}$ は解析領域 $\left[\mathrm{L}^{3}\right]$ である。Celia and Bouloutas (1990) は高次 項を無視して $S_{\mathrm{w} j}{ }^{n+1, m+1}$ を以下のようにテイラー展 開した。

$$
S_{w j}^{n+1, m+1}=S_{w j}^{n+1, m}+\left.\frac{\partial S_{w}}{\partial \psi_{w}}\right|^{n+1, m}\left(\psi_{w j}^{n+1, m+1}-\psi_{w j}^{n+1, m}\right)
$$

ここで、 $\partial S_{w} / \partial \psi_{w}$ は飽和度とサクションで表し た水分特性曲線の勾配となる。間隙率が水圧など により変化しないと仮定し、 $\partial S_{w} / \partial \psi_{w}$ に間隙率 を乗ずると比水分容量 $\mathrm{C}\left(\psi_{w}\right)=\partial n \mathrm{~S}_{w} / \partial \psi_{w}=$ $\partial \theta_{w} / \partial \psi_{w}$ となる。式 (12) を式 (11) に代入して 整理すると以下の式（13）を得ることができる。

$$
\begin{aligned}
& \left\{\frac{\alpha S_{s}}{\Delta t} \sum_{j=1}^{n p} \int_{V} \phi_{i} \phi_{j} d V+\left.\frac{n}{\Delta t} \frac{\partial S_{w}}{\partial \psi_{w}}\right|^{n+1, m} \sum_{j=1}^{n p} \int_{V} \phi_{i} \phi_{j} d V\right. \\
& +\sum_{j=1}^{n p}\left(\int_{V} \bar{k}_{r}\left(\theta_{w}\right)^{n+1, m} K_{s} \frac{\partial \phi_{i}}{\partial x} \frac{\partial \phi_{j}}{\partial x} d V\right. \\
& +\int_{V} \bar{k}_{r}\left(\theta_{w}\right)^{n+1, m} K_{s} \frac{\partial \phi_{i}}{\partial y} \frac{\partial \phi_{j}}{\partial y} d V \\
& \left.\left.+\int_{V} \bar{k}_{r}\left(\theta_{w}\right)^{n+1, m} K_{s} \frac{\partial \phi_{i}}{\partial z} \frac{\partial \phi_{j}}{\partial z} d V\right)\right\} \delta_{\mathrm{w} j}^{n+1, m+1}
\end{aligned}
$$




$$
\begin{aligned}
& =-\left\{\alpha S_{s} \sum_{j=1}^{n p} \int_{V} \phi_{i} \phi_{j} d V \frac{\psi_{w j}^{n+1, m}-\psi_{w j}^{n}}{\Delta t}\right. \\
& +n \sum_{j=1}^{n p} \int_{V} \phi_{i} \phi_{j} d V \frac{S_{w j}^{n+1, m}-S_{w j}{ }^{n}}{\Delta t} \\
& +\sum_{j=1}^{n p}\left(\int_{V} \bar{k}_{r}\left(\theta_{w w}\right)^{n+1, m} K_{s} \frac{\partial \phi_{i}}{\partial x} \frac{\partial \phi_{j}}{\partial x} d V\right. \\
& +\int_{V} \bar{k}_{r}\left(\theta_{w}\right)^{n+1, m} K_{s} \frac{\partial \phi_{i}}{\partial y} \frac{\partial \phi_{j}}{\partial y} d V \\
& \left.+\int_{V} \bar{k}_{r}\left(\theta_{w}\right)^{n+1, m} K_{s} \frac{\partial \phi_{i}}{\partial z} \frac{\partial \phi_{j}}{\partial z} d V\right) \psi_{j}^{n+1, m} \\
& \left.+\int_{V} \rho_{n v} \bar{k}_{r}\left(\theta_{w}\right)^{n+1, m} K_{s} \frac{\partial \phi_{i}}{\partial z} d V-q_{w i}\right\} \quad(i=1 \sim n p)
\end{aligned}
$$

ここで、 $\delta_{w j}{ }^{n+1, m+1}=\psi_{w j}{ }^{n+1, m+1}-\psi_{w j}{ }^{n+1, m}$ とする。

式 (13) の右辺は最新の非線形の繰り返し回数 $m+1$ の前の繰り返し回数である $m$ における式

（5）の離散化式となっている。 $\psi_{\mathrm{w} j}^{n+1, m+1}$ が収束す る過程で $\delta_{w j}{ }^{n+1, m+1}=\psi_{w j}{ }^{n+1, m+1}-\psi_{w j}{ }^{n+1, m} \approx 0$ となり、 最終的に式（13）の左辺は以下の式（14）のよう にほぼ0となる。

$$
\begin{aligned}
& \left\{\alpha S_{s} \sum_{j=1}^{n p} \int_{V} \phi_{i} \phi_{j} d V \frac{\psi_{w i j}^{n+1, m}-\psi_{w j}^{n}}{\Delta t}\right. \\
& +n \sum_{j=1}^{n \phi_{V}} \int_{V} \phi_{i} \phi_{j} d V \frac{S_{w j}^{n+1, m}-S_{w j}^{n}}{\Delta t}+\sum_{j=1}^{n p}\left(\int_{V} \bar{k}_{r}\left(\theta_{w}\right)^{n+1, m} K_{s} \frac{\partial \phi_{i}}{\partial x} \frac{\partial \phi_{j}}{\partial x} d V\right. \\
& +\int_{V} \bar{k}_{r}\left(\theta_{w}\right)^{n+1, m} K_{s} \frac{\partial \phi_{i}}{\partial y} \frac{\partial \phi_{j}}{\partial y} d V \\
& \left.+\int_{V} \bar{k}_{r}\left(\theta_{w}\right)^{n+1, m} K_{s} \frac{\partial \phi_{i}}{\partial z} \frac{\partial \phi_{j}}{\partial z} d V\right) \psi_{j}^{n+1, m} \\
& \left.+\int_{V} \rho_{r w} \bar{k}_{r}\left(\theta_{w}\right)^{n+1, m} K_{s} \frac{\partial \phi_{i}}{\partial z} d V-q_{w i}\right\} \approx 0 \quad(i=1 \sim n p)(14)
\end{aligned}
$$

式（14）は式（5）をガラーキン型有限要素法で 定式化した式となり、式（14）のマスバランスは 非線形の繰り返し回数 $m+1$ を $m$ とした式 (9)
となるので式 (13) のマスバランスが保持される。 式 (13) は $\delta_{\mathrm{w} j}{ }^{n+1, m+1}$ のみが変数となるので解くこ とができ、最新の繰り返し回数で求めた $\delta_{\mathrm{w} j}{ }^{n+1, m+1}$ に前の繰り返し回数の水の圧力水頭 $\psi_{\mathrm{w} j}{ }^{n+1, m}$ を加 えれば、最新の繰り返し回数の水の圧力水頭 $\psi_{\mathrm{w} j}{ }^{n+1, m+1}$ が求められる。

\section{3. 不飽和特性の表現}

式（5）や式（8）では、不飽和特性を表す水分 特性曲線と呼ばれる水のサクションと体積含水率 (または水の飽和度)の関係と体積含水率（または 水の飽和度）と相対透過度の関係が必要である。 水分特性曲線については、地盤工学会 (2000) で 「JGS 0151-2000 土の保水性試験」で試験方法が 基準化されている。また、水分特性曲線を求める 試験方法は $\mathrm{pF}$ 試験とも呼ばれることがあり、 $\mathrm{pF}$ 試験ではサクションの絶対值の常用対数となる $\mathrm{pF}$ 值を求める。体積含水率と相対透過度の関係 を求める不飽和土の透水試験方法については、基 準化されたものはないが地盤工学会（2000）の 「土質試験の方法と解説」で試験方法の原理を簡 潔にまとめている。また、最適化のための水分特 性曲線モデルとしてVan Genuchten モデルや Brooks-Corey モデルが提案されている。Van Genuchten モデルは以下の式となり、これにより得 られる水分特性曲線の例を図 4 に示す。

$$
S_{w e}=\frac{\left(S_{w}-S_{w r}\right)}{\left(1-S_{w r}\right)}=\frac{1}{\left\{1+\left(\alpha\left|\psi_{w}\right|\right)^{\beta}\right\}^{\gamma}} \psi_{w} \leq 0
$$

ここで、 $\mathrm{S}_{\mathrm{we}}$ は水の有効飽和度、 $S_{\mathrm{wr}}$ は水の残留 飽和度である。また、 $\alpha 、 \beta 、 \gamma(=1-1 / \beta)$ は Van Genuchten モデルの定数となり、これらの 定数は土に固有の定数である。一方、BrooksCoreyモデルは以下の式のようにVan Genuchten モデルの式より若干シンプルな式となる。

$$
\bar{S}_{\mathrm{w}}=\left(\frac{\psi_{\mathrm{d}}}{\left|\psi_{\mathrm{w}}\right|}\right)^{\lambda} \psi_{w}<-\psi_{d} \leq 0
$$

ここで、 $\psi_{\mathrm{d}}$ は浸入圧力、入は間隙のサイズの指 数である。図 4 には、Van Genuchten モデルで求 めた水分特性曲線とともに、Brooks-Coreyモデル より求めた水分特性曲線も示されている。図 4 よ 


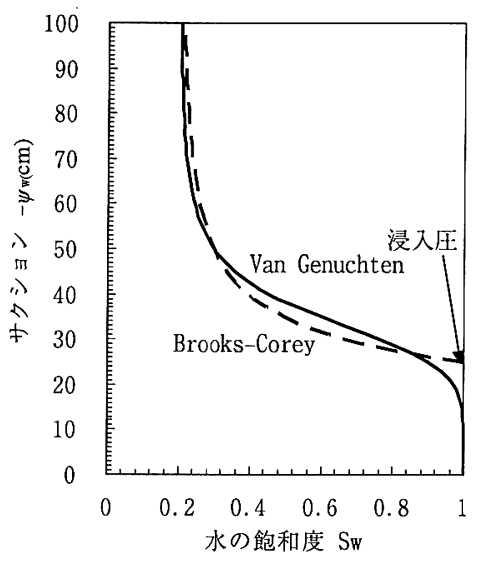

(a)水分特性曲線

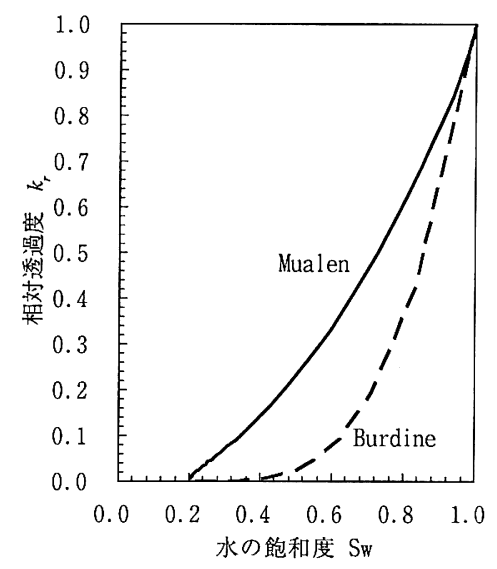

(b) 飽和度一相対透過度

図 4 不飽和特性

り分かるようにVan Genuchten モデルの式（15） は飽和状態で 0 となる連続関数であるが、 Brooks-Corey モデルは飽和状態で浸入圧力 $\psi_{\mathrm{d}}$ を 持つことが分かる。どちらのモデルを選択するか によって解析結果が若干異なる場合がある。 $\psi_{\mathrm{d}}$ は飽和された土が排水せずに保水できる限界のサ クションである。実際の土では、圧力水頭が 0 と なる地下水位より高い位置に飽和带（キャピラリ バリアー）が存在する場合があり、その高さに相 当する圧力水頭が $\psi_{\mathrm{d}}$ となる。

一般的に、非濡れ相流体 (NAPL や気体) など を扱う多相流では Brooks-Corey モデルを使う場 合が多い。式（15）と式（16）の $\alpha 、 \beta 、 \psi_{\mathrm{d}} 、 \lambda$ の定数は、一般的に実験結果に最適化させること により得ることができる。以前は、実験結果で得 られた水分特性曲線を折れ線グラフで近似して用 いていた時代があるが、この手法では折れ線グラ フの折れ点で水分特性曲線の微分值が不連続（比 水分容量が階段状の関数）となるために、折れ線 グラフで近似された水分特性曲線を用いて式（8） を有限要素法などで解くと解が発散することがあ る。

水の飽和度と相対透過度の関係のモデルとして は、Van Genuchten モデルを基に求めた Mualem モデル、

$$
K_{r w}=S_{w e}^{1 / 2}\left\{1-\left(1-S_{w e}^{1 / \gamma}\right)^{\gamma}\right\}
$$

および Brooks-Corey モデルを基に求めた以下の Burdine モデル、

$$
k_{\mathrm{rw}}=\bar{S}_{\mathrm{w}}(2+3 \lambda) / \lambda
$$

がある。

また、これらのモデルで求めた水の飽和度と相 対透過度の関係の例を図 4 に示す。図 4 から分か るように、Mualem モデルと Burdine モデルで求 めた水の飽和度と相対透過度の関係には若干ずれ が生じている。なお、上記の不飽和特性について は、Helmig （1997）が大変参考になる。

\section{4. 最後に}

飽和・不飽和流れの支配方程式の種類やその特 徵があまり一般に知られていないことに度々気が 付くことがある。この機会に、上記のことを踏ま えて実務の浸透流解析などを行って頂けることを 著者としては望みたい。なお、不飽和の地下水の 流れの支配方程式を飽和度のみで表す飽和度型方 程式もあることを追記しておく。

\section{参考文献}

赤井浩一 ·大西有三 - 西垣 誠 (1997)：有限要素法に よる飽和一不飽和浸透流の解析、土木学会論文報告 集、第264号、pp. 171-179.

地盤工学会（2000）: 土質試験の方法と解説、地盤工学 
会.

P. A. ドミンゴ、F.W. シュワルツ（地下水の科学研究会 大西有三監訳)（1995）：地下水の科学 I 、土木工学 社.

日比義彦、藤縄克之、藤原幸彦（2002）：多孔体中にお ける水 - NAPL 2 相流の数值モデルの比較、土木学 会論文集、No. 720/ III-25、pp. 25-38.
Celia, M. and Bouloutas, E.T. (1990): A General massconservative numerical solution for the unsaturated flow equation, Water Resources Research, Vol.26, No7, pp. 1483-1496.

Helmig, R. (1997): Multiphase Flow and Transport Process in the Subsurface, Springer.

（受付：2008年 6 月13日、受理：2008年 7 月14日） 